\title{
The role of Brazilian National Health Information Systems in assessing the impact of Zika virus outbreak
}

\author{
Ana Luiza Braz Pavão ${ }^{[1]}$, Christovam Barcellos ${ }^{[1]}$, Marcel Pedroso ${ }^{[1]}$, \\ Cristiano Boccolini ${ }^{[1]}$ and Dália Romero ${ }^{[1]}$
}

[1]. Laboratório de Informação em Saúde, Instituto de Informação e Comunicação Científica e Tecnológica em Saúde, Fundação Oswaldo Cruz, Rio de Janeiro, RJ, Brasil.

\begin{abstract}
The Zika virus (ZIKV) epidemic has become a public health emergency following its association with severe neurological complications. We aim to discuss how the Brazilian National Health Information Systems can help to assess the impact of the ZIKV epidemic on health outcomes potentially related to ZIKV. Health outcomes potentially related to ZIKV infection were described based on a literature review of published studies on ZIKV infection outcomes and on recent protocols developed and published by the Brazilian Ministry of Health for different stages of the life cycle. These outcomes were correlated with the International Classification of Diseases 10th Revision (ICD-10) classification system, as this is the diagnostic classification registered in the Health Information System. A suggested list of 50 clinical manifestations, dispersed into 4 ICD chapters, and their information sources was created to help monitor the ZIKV epidemics and trends. Correlation of these selected ICD-10 codes and the HIS, as well as, a review of the potentialities and limitations of health information systems were performed. The potential of the Health Information System and its underutilization by stakeholders and researchers have been a barrier in diagnosing and reporting ZIKV infection and its complications. The ZIKV outbreak is still a challenge for health practice and the Brazilian Health Information System.
\end{abstract}

Keywords: Zika virus. Infection. Outbreak. Brazil. Health information systems.

\section{INTRODUCTION}

The Zika virus (ZIKV) epidemic has become a public health emergency. Recent studies have shown that ZIKV infection damages the central nervous system, causing fetal malformations $^{1}$ and certain neuropathies such as GuillainBarré Syndrome ${ }^{2-5}$. The virus's neurotropic behavior and its ability to cross the placental barrier and cause brain damage during fetal development have been demonstrated in laboratory experiments ${ }^{6,7}$.

$\mathrm{ZIKV}$ is an arthropod-borne virus, and the key vectors for its natural transmission are Aedes aegypti and Aedes albopictus ${ }^{8,9}$, the same vectors of other febrile illnesses, such as dengue and chikungunya ${ }^{10,11}$. Recently, ZIKV infection has also been associated with several neurological complications, including microcephaly ${ }^{5,7,12}$. The virus was first isolated from rhesus monkeys in the Zika Forest of Uganda, Africa, in $1947^{13}$. In 2007, an outbreak of ZIKV disease occurred on Yap Island, Federated States of Micronesia. In this outbreak, mild symptoms

Corresponding author: Dra. Ana Luiza Braz Pavão.

e-mail: ana.pavao@icict.fiocruz.br

Received 5 December 2016

Accepted 2 June 2017 were commonly observed, such as rash, fever, arthralgia, and conjunctivitis. No neurological complications or deaths were reported ${ }^{14}$.

From October 2013 to early 2014, an outbreak of ZIKV disease occurred in French Polynesia, with a large number of symptomatic patients and severe cases, including neurological disorders ${ }^{2}, 15$. Until this epidemic, no severe cases of ZIKV disease had been described ${ }^{2}$. Forty-two cases of Guillain-Barre Syndrome (GBS) were reported during the outbreak in French Polynesia ${ }^{15,16}$. According to Weaver et al., after this epidemic, ZIKV reached several other islands in Oceania, including New Caledonia, the Cook Islands, and Easter Island ${ }^{16}$.

In Brazil, an outbreak of a febrile rash illness of unknown etiology appeared in October 2014 in Rio Grande do Norte, northeastern Brazil. The clinical manifestations were low fever or no fever, maculopapular rash, pruritus, arthralgia, and limb edema $^{17}$. In early 2015, in Camaçari, Bahia, Brazil, a similar outbreak was described ${ }^{18}$. In May 2015, ZIKV was confirmed by reverse transcription-polymerase chain reaction (RT-PCR) tests in samples from patients in the states of Bahia, and Rio Grande do Norte ${ }^{8,17,18}$.

Studies reported a high identity between sequences of ZIKV circulating in Brazil and the ZIKV Asian lineage ${ }^{8,19-21}$. Some authors report the hypothesis of introduction of ZIKV in Brazil 
during the 2014 World Cup soccer competition ${ }^{8,22}$; however, Musso argued that, since there no ZIKV-endemic Pacific countries competed in the 2014 World Cup, ZIKV was most likely introduced after the Va'a World Sprint Championship canoe race held in Rio de Janeiro, southeastern Brazil, where four Pacific countries in which ZIKV circulated during 2014 participated in this competition ${ }^{23}$.

During the 2013 outbreak in French Polynesia, neurological complications after ZIKV disease were described ${ }^{24}$. However, Brazil was the first country to report a high increase in the incidence of fetal microcephaly, especially in the State of Pernambuco. By January 2016, a total of 3,530 suspected cases of microcephaly had been reported to the Brazilian Ministry of Health. According to Oliveira et al., the peak number of microcephaly cases coincided with cases of a febrile rash illness compatible with ZIKV disease, considering a pregnancy duration of 38 weeks ${ }^{4}$. Until early April 2016, a total of 1,384 cases of microcephaly and/or other congenital malformations had been confirmed in Brazil, $89 \%$ of them in the northeastern region $^{25}$.

A previous time-series analysis of data from the Brazilian Hospitalization System indicated an unprecedented increase in hospitalizations in the northeastern region due to several neuropathies starting in mid-2014. In this study, hospitalizations registered with several International Classification of Diseases (ICD) codes, and even different chapters, were considered. This finding suggests that identifying ICD codes potentially related to ZIKV infection might be able to answer the new challenges posed by ZIKV epidemics, bringing evidence about the relevance of using health information systems to capture possible traces of ZIKV infections related to neurological complications ${ }^{26}$.

Population health information systems may have a major impact in promoting health actions, programs and policies as they can improve the decision-making process through data analysis. The Brazilian National Health Information Systems (HIS) cover the entire life cycle, from birth to death, and can be used to analyze the health situation and trends in different Brazilian regions, identifying potential epidemics and their impacts on health outcomes.

\section{BRAZILIAN HEALTH INFORMATION SYS- TEMS COVER LIFE CYCLES}

It is important to note that the HIS covers several stages of the population life cycle, as shown in Figure 1. Health professionals can search for information regarding a specific disease outbreak or its associated complications from multiple sources and stages of the life cycle, such as prenatal period, birth, childhood, adulthood, old age, and death. For each stage of the life cycle, different health systems can be assessed and used, depending on the information one is searching for. For example, there is information about the mortality of newborns in the Mortality Information System (SIM), information on pregnancy and childbirth in the Live Birth Information System (SINASC), and information on newborn hospitalizations in the Hospital Information System (SIH).

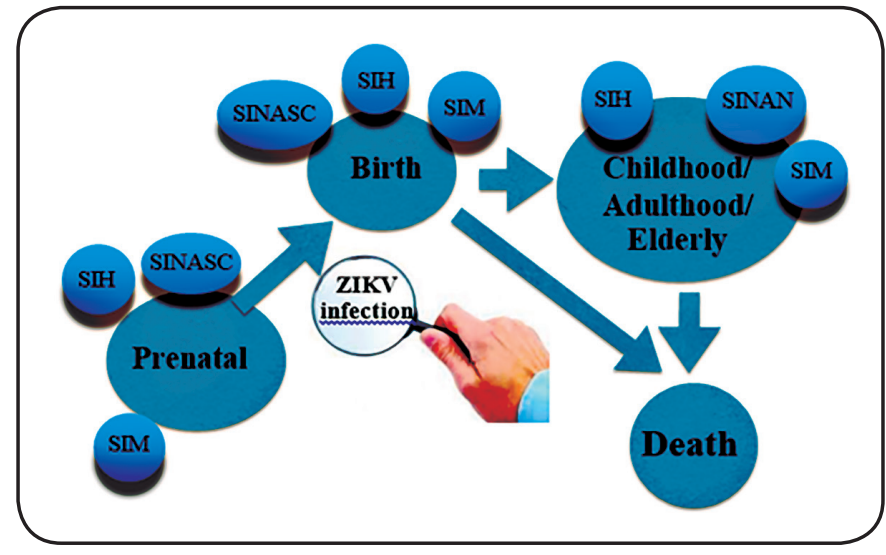

FIGURE 1 - Brazilian Health Information Systems (SIM, SINASC, SIH, SIAB, and SINAN) where indicators of ZIKV infection could be found in different stages of life. ZIKV: Zika virus; SIM: Mortality Information System; SINASC: Live Birth Information System; SIH: Hospital Information System; SIAB: Primary Care Information System; SINAN: Notifiable Diseases Information System.

Figure 1 shows the Brazilian HIS where indicators of ZIKV infection can be found in different stages of the life cycle: the SIM, SINASC, SIH, Primary Care Information System (SIAB), Notifiable Diseases Information System (SINAN), and Public Health Events Registry (RESP). Although health professionals can find information regarding different life stages using the HIS, it is not possible to follow-up one patient in different life stages, as the information is available for population levels.

Eventually, in the context of outbreaks, the Ministry of Health can develop complementary health systems, such as the RESP, created in response to ZIKV outbreak. This system covers information related to pregnancy and childbirth, and is filled online by health professionals, making the registration of such events easier and faster.

The RESP is a web form developed by Departamento de Informática do Sistema Único de Saúde (DATASUS) to record public health events related to ZIKV infection such as microcephaly. Even though this form is not an information system itself, it generates useful information for the SINASC. Per the protocols of the Brazilian Ministry of Health, suspected cases of microcephaly, related or unrelated to ZIKV infection, should be reported by public and private health facilities using RESP. Furthermore, these cases still need to be reported in the SINASC $^{27,28}$.

\section{A REVIEW OF ICD CODES IN THE CON- TEXT OF ZIKV OUTBREAKS AND ASSO- CIATED COMPLICATIONS}

We reviewed the ICD-10 codes potentially related to ZIKV and its complications to provide tools for searching for health information in those systems, and to indicate which system could provide each information (Table 1 and Table 2). The correct description of ICD codes, their search in health systems and further analysis are essential to the success of the research and the quality of the results found. Furthermore, ICD code identification, description and understanding can 
TABLE 1

Health outcomes potentially associated with the ZIKV outbreak, by ICD-10 code: viral infections, and neurological manifestations.

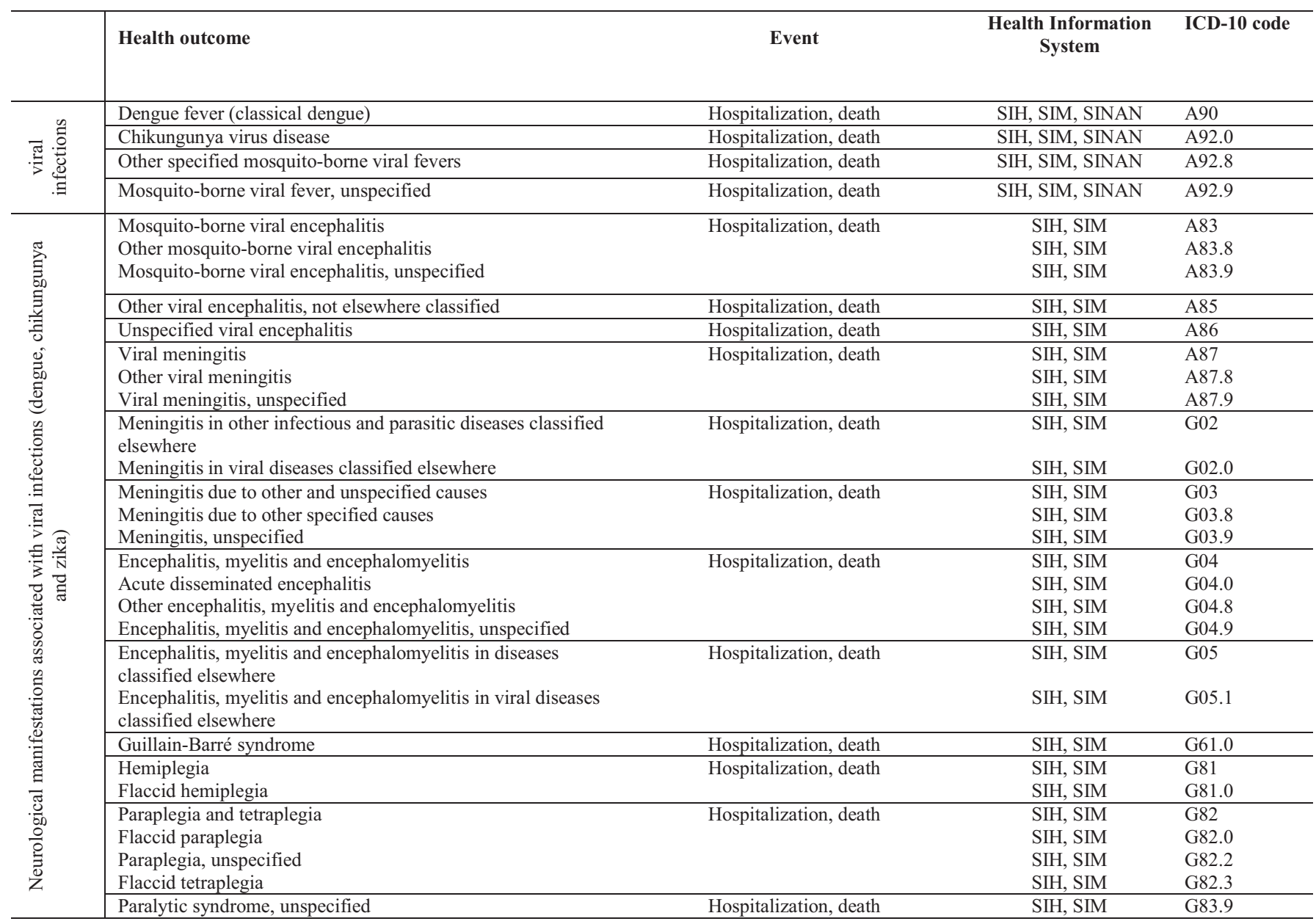

ZIKV: Zika virus; ICD-10: International Classification of Diseases 10; SIH: Hospital Information System; SIM: Mortality Information System; SINAN: Notifiable Diseases Information System. *Data available from February, 2016.

help evaluate the impact of the ZIKV epidemic and its associated complications, and can also be used to build a dashboard to monitor ZIKV epidemics and trends.

Therefore, initially, health outcomes potentially related to ZIKV infection were selected based on a literature review of published studies on ZIKV outbreaks and recent protocols developed and published by the Brazilian Ministry of Health for different stages of the life cycle ${ }^{27,28}$. These health outcomes were correlated with the ICD-10 (2007 version), as this is the diagnostic classification registered in the Brazilian HIS ${ }^{29}$. These selected ICD-10 codes were correlated with distinct systems in the Brazilian HIS in the following stage.

Regarding birth outcomes, the Brazilian Ministry of Health's Surveillance and Response Protocol for microcephaly investigates cases with one of the following characteristics: newborn with microcephaly; stillborn with microcephaly and/or central nervous system malformations suggestive of congenital infection; spontaneous abortion suggestive of congenital infection; and fetus with microcephaly and/or central nervous system malformations suggestive of congenital infection $^{28}$. The Surveillance Protocol of cases with neurological manifestations with a previous viral infection history defines suspected cases as patients attending the surveillance unit with neurological problems of unknown origin and reporting a prior viral infection up to 60 days before the onset of neurological problems. In this protocol, neurological manifestations are defined by the following diagnoses: encephalitis, meningoencephalitis, myelitis, acute flaccid paralysis, acute disseminated encephalomyelitis (ADEM), and $\mathrm{GBS}^{27}$.

After describing the health outcomes potentially associated with the ZIKV epidemic using ICD-10 codes, we identified related events (such as hospitalizations and deaths) that could be detected and reported, and the section of the Brazilian HIS where they could each be found.

Table 1 and Table 2 show health outcomes with their respective ICD-10 codes potentially related to the ZIKV outbreak in Brazil, in four domains: viral infections, neurological manifestations associated with viral infections (dengue, chikungunya, and zika disease), types of abortions potentially associated with ZIKV infection, and congenital malformations associated with ZIKV infection, based on the evidence presented in the paragraphs below. 
Pavão ALB et al. - Health information system and Zika virus outbreak

TABLE 2

Health outcomes potentially associated with the ZIKV outbreak, by ICD-10 code: types of abortion and congenital malformations.

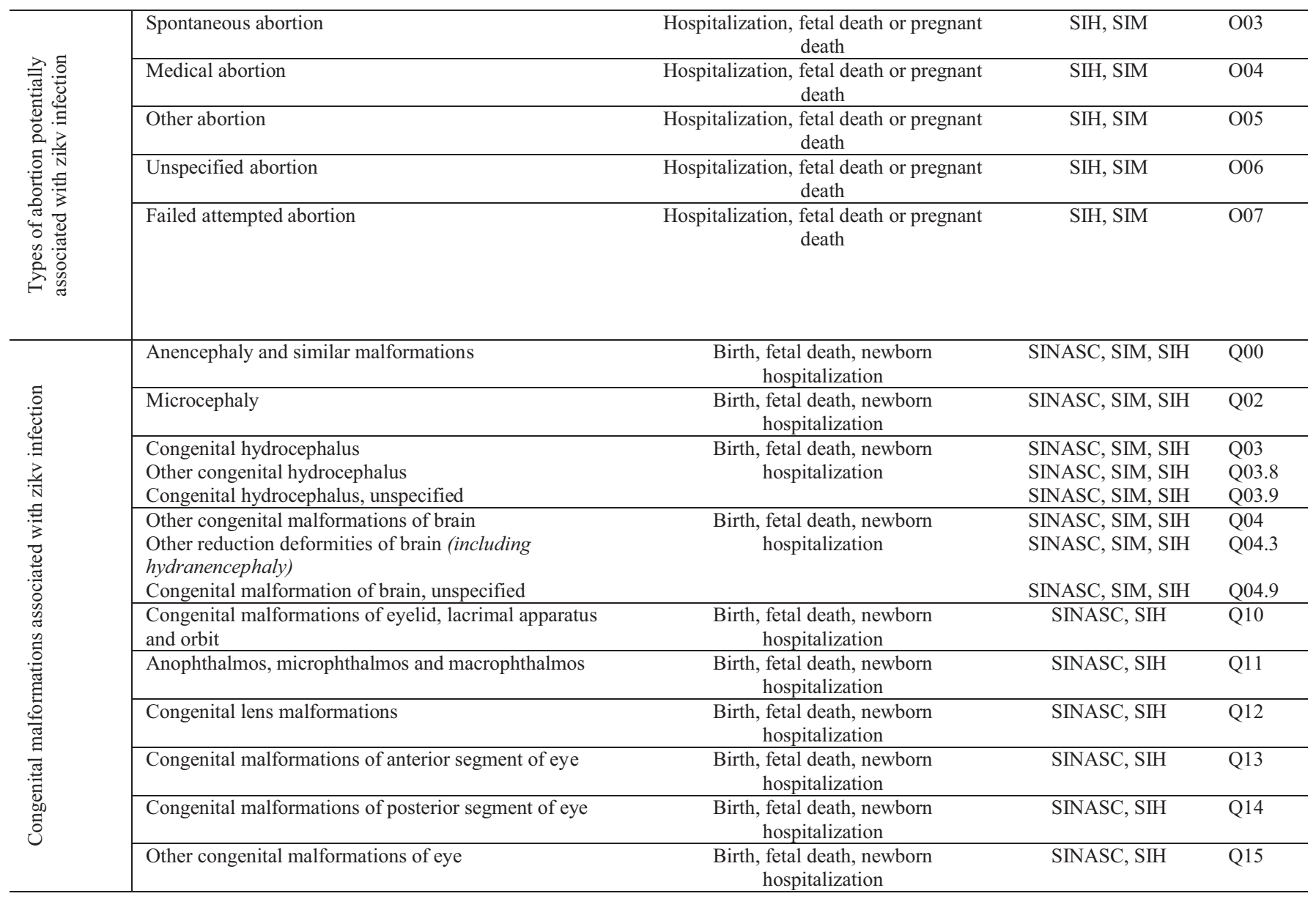

ZIKV: Zika virus; ICD-10: International Classification of Diseases 10; SIH: Hospital Information System; SIM: Mortality Information System; SINASC: Live Birth Information System. *Data available from February, 2016.

In Brazil, besides ZIKV disease, dengue and chikungunya may also play a role in the ZIKV outbreak, as there is evidence of co-circulation of the three viruses ${ }^{21}$. Therefore, it is important to investigate the neurological manifestations associated with different viral infections, especially dengue, chikungunya, and ZIKV infection. Throughout the list, we considered the possibility of uncertainty among healthcare professionals when filling out health forms with ICD-10 codes; we, therefore, included some non-specific ICD-10 categories to circumvent this issue.

Many studies have suggested a possible association between ZIKV disease and microcephaly ${ }^{7,30}$. A recent laboratory study showed that ZIKV affects human brain cells, reducing their viability and growth ${ }^{31}$. ZIKV disease has also been associated with other neurological complications, including GBS $^{15,32}$, meningoencephalitis ${ }^{33}$, microcephaly with agyria and hydrocephalus ${ }^{7}$, hydranencephaly, intracranial calcifications $s^{5,7}$, and ocular findings such as bilateral macular and perimacular lesions, and optic nerve abnormalities ${ }^{34}$.

Furthermore, two cases of ADEM have been found to be associated with ZIKV disease in an as yet unpublished study conducted in Recife, Pernambuco, Brazil. To assess the association between ZIKV disease and GBS, a casecontrol study was conducted in French Polynesia to compare laboratory-confirmed ZIKV antibodies among GBS cases and controls. The authors found that $98 \%$ of patients with GBS had ZIKV antibodies, compared to only $56 \%$ among the controls, a statistically significant result ${ }^{32}$.

We believe the association between ZIKV infection and abortion should be assessed, as it is not implausible to assume that women whose fetuses are found to have congenital malformations (e.g. microcephaly), or are aware of this risk, may opt for an abortion. Moreover, some studies have suggested that severe congenital malformations may be related to spontaneous abortion or fetal demise $\mathrm{s}^{5,35}$.

Finally, congenital malformations associated with ZIKV infection described in recent studies $s^{4,5,6,7,30,34}$ and a protocol of the Brazilian Ministry of Health ${ }^{28}$ were classified according to ICD10. These include a broad range of congenital malformations of the brain and eye. 


\section{POTENTIALITIES AND LIMITATIONS OF HEALTH INFORMATION SYSTEMS}

The ZIKV outbreak is a challenge for health practice. The Brazilian Health Surveillance System has been facing difficulties in diagnosing and reporting ZIKV infection and its complications. These represent difficulties in promptly detecting ZIKV health effects similar to those of other countries in which ZIKV is spreading, with the infection not being properly and timely confirmed by laboratory tests. The symptoms of ZIKV infection can be similar to other infectious diseases including dengue and chikungunya. Currently available laboratory tests are expensive, may cross-react with other etiologic agents, and are limited to the first weeks after infection. However, several neurological complications have been described in ZIKVinfected individuals. In future, as further studies are published, the classification system of diseases may need to be changed.

Similarly, as new evidence emerges about the disease and its pathogenesis, the health outcomes potentially associated with ZIKV infection (Table 1 and Table 2) may be modified, confirmed, discarded, or replaced. At present, these outcomes are considered by the authors as potentially related to ZIKV infection and may be useful as markers of information about the disease (and its epidemic situation in Brazil) in the main Brazilian Information Systems, in a context where the disease and its determinants are still incompletely understood.

All of these health outcomes can be properly detected and recorded in information systems during health events when a person receives medical care in a healthcare facility. Health events such as births, hospitalizations, outpatient visits, and deaths represent opportunities for diagnosing and recording ZIKV infection and potentially associated neurological complications. These events are obviously associated with the provision of health services and rely on patients entering the healthcare system. Therefore, an initial barrier to diagnosing and recording health problems associated with ZIKV infection is access to health services and their quality.

Since the HIS captures isolated health events in different data sources, it is impossible to follow up the development of disease and its manifestations at the individual level. New investments can be made to link these events and allow for longterm monitoring of people affected by ZIKV. It is exactly these opportunities for diagnosing and recording ZIKV infection and potentially associated neurological complications which we are attempting to capture using data science strategies and tools, as shown in Figure 1.

Data science applied to health ${ }^{36-38}$ is a promising field of study due to its ability to provide useful information from large and diverse databases. It comprises a set of strategies and techniques that bring together multidisciplinary teams with knowledge of the problem and on methods, including, statistical, mathematical and scientific computing. It combines traditional methods of analysis with sophisticated algorithms to process large volumes of data in various formats; structured and unstructured. This process of data analysis involves I) extracting, transforming and loading data; II) selection of records and creation of data subsets; III) pre-processing, linkage, and data cleansing and enrichment; IV) transformation, reduction and standardization; and V) data mining through classification, association, clustering, anomaly detection and prediction; VI) interpretation of patterns, filtering and visualization, coupled to decision support systems. This set of techniques and knowledge may contribute to support health surveillance activities and epidemiological studies about Zika and potentially associated neuropathies. Besides the large amount of data on the usage of the Brazilian Unified Health System (SUS), it is important to add general information to outline scenarios and conditions in which the disease processes take place, by integrating available information from external databases, such as social networks, blogs and digital media, as well as environmental and climatic data, which will be produced and associated with health data through geographic information systems and spatial analysis tools.

Another limiting factor for adequately diagnosing and recording these health outcomes is the context in which they are produced. The data included in the SINASC is gathered from birth declarations, which are filled soon after birth. About 95\% of births in Brazil are recorded in this system, with $85 \%$ of births occurring in hospital settings. There is, therefore, a high coverage of birth records, but this does not guarantee adequate reporting of birth defects. Furthermore, as the SINASC's updating time for newborns can be as high as 90 days, other reporting methods need to be developed for public health emergencies, such as the RESP, to help collect and compile data and characterize the emergency ${ }^{28}$. Studies in Brazil have suggested under-reporting of about $40 \%$ for congenital anomalies in live births ${ }^{39}$. The World Health Organization estimates that about 2 to $3 \%$ of children are born with some congenital anomaly; in Brazil, this percentage is $0.8 \%$, according to SINASC data. Regarding microcephaly, measurement of brain diameter in the first hours after birth can produce a large number of false positives ${ }^{39}$. However, a recent study, which evaluated the SIM and SINASC, showed improvement in adequacy levels of information from 2008-2010, compared to 1999-200140. Confirmation of severe and irreversible microcephaly can only be done through additional tests and adequate follow-up, and is not recorded in the birth declaration. With the increasing number of congenital malformations associated with Zika, the number of congenital anomalies should approach expected levels as the reporting system improves ${ }^{41}$.

Fetal and neonatal deaths can be retrieved in the SIM, but this system has further problems, such as low coverage and poor reporting of the primary cause of death ${ }^{42}$. A large number of fetal or neonatal deaths occur outside the hospital, and under no medical care, which complicates the assessment of congenital malformations using this information system.

The SIH records hospitalizations in public and private hospitals in Brazil associated with the SUS. Payment for these services is done after the SUS issues and certifies an Authorization for Hospitalization. Since this is a public healthcare system, hospitalizations cover most of the needs of the low-income population, but not about $25 \%$ of the 
population who are privately insured ${ }^{43}$ or who pay out-ofpocket for private services, as only about $71 \%$ of Brazilians use the SUS as their main healthcare provider. The SIH includes financial and administrative information, as it is used for reimbursing expenses. It is occasionally used as a source of epidemiologic data, but can be used as a secondary data source for conducting research and epidemiologic surveillance. Still, because of the high coverage of these services, relatively stable and standardized data production, and rapid production and dissemination of data through TABNET/DATASUS, it can be used as an epidemiological alert system, especially for severe infectious diseases ${ }^{44,45}$.

The SIH records hospital procedures, initial diagnosis, primary and secondary diagnoses, and the cause of death (if applicable). These fields can be used to examine possible neurological complications of ZIKV infection (Table 1). However, it should be noted that the diagnosis is recorded in the first days of hospitalization or soon after discharge, although it can be changed throughout the hospital stay after additional tests are performed, such as imaging tests and laboratory confirmation of the infection. Adequate diagnosis and reporting of ICD codes depends on the complexity of the procedures and the quality of health services, which can be a complicating factor in the case of neuropathies.

The HIS can provide important information for analyzing and monitoring the impact of ZIKV transmission on the health of the population. However, there is a lag between the production and release of data from national information systems; for the SIH and SINAN, the release of data can take a few months, while for the SIM and SINASC, this delay can be up to two years or more.

On the other hand, public health alerts have a great potential for changing health care practices and the way they are recorded. In future, false outbreaks of diseases related to ZIKV infection may arise, due to greater attention to clinical pictures previously overlooked or incorrectly reported. The broad press coverage of malformations, especially microcephaly and, to a lesser extent, neuropathies such as GBS, puts pressure on the health system, with pregnant women, healthcare providers, researchers, and governments playing a central role. Investigation of a possible relationship between the various neurological problems mentioned here and ZIKV infection is becoming routine in health services and causing anxiety among patients.

Future research based on the retrieval and matching of historical series should consider potential over-reporting, changes in the way causes are reported, new diagnostic methods and clinical and laboratory routines, and the effect of changes in the quality of reporting of Zika-associated diseases.

Several causes for hospitalization have been reported in the absence of a diagnostic protocol for neurological complications caused by ZIKV infection ${ }^{26}$. In future, with the introduction of new clinical entities to the ICD list and their incorporation into health service practices, a new profile of diseases to be reported and recorded in information systems will probably emerge. The World Health Organization recommends, since December 2015, that ZIKV infection is classified under codes U06 (Zika virus disease) or U06.9 (Zika virus disease, unspecified) ${ }^{46}$.
Until the end of 2015, a set of clinical manifestations were used to represent the neurological complications of ZIKV infection, not only due to difficulties in laboratory diagnosis (because there was no test to detect the infection), but also because no alert had been issued regarding the epidemic. PCR is currently used, but it is expensive and only used for detecting recent infections. These data are scattered over the various national HIS, under different names and covering diverse health events, such as hospitalizations, deaths (fetal or not), births, and clinical and laboratory tests, making assessment of this information challenging.

It must be noted that during the epidemic and because of the epidemiological alerts, there should be a migration of the basic causes (classified according to ICD-10) of major health events recorded in HIS: births and malformations, hospitalizations due to neurological problems, births and spontaneous abortions, deaths due to neuropathies, and arbovirus infections. With the introduction of new standards and diagnostic procedures and the publication of alerts about the new epidemic, the reporting of ZIKV infection-related neuropathies is likely to increase, using a new taxonomy and case classification.

Before the Zika epidemics, diagnosing neuropathies was not a priority for health systems and even less so for the information systems of the SUS. The introduction of new routine procedures and protocols may change the accuracy of diagnosis, affecting the quality of morbidity indicators for neuropathies. We believe that the HIS is currently underutilized and an appropriate understanding of its role by health professionals, stakeholders and researchers can help to produce and analyze information regarding important diseases, especially recent outbreaks and their associated complications, such as ZIKV infection.

\section{Conflict of interest}

The authors declare that there is no conflict of interest.

\section{REFERENCES}

1. Brasil P, Pereira Jr JP, Raja-Gabaglia C, Damasceno L, Wakimoto M, Ribeiro-Nogueira RMR, et al. Zika virus infection in pregnant women in Rio de Janeiro: preliminary report. N Engl J Med. 2016; March 8, p. 1-11. doi: 10.1056/NEJMoa1602412.

2. Ioos S, Mallet HP, Leparc Goffart I, Gauthier V, Cardoso T, Herida M. Current Zika virus epidemiology and recent epidemics. Med Mal Infect. 2014;44(7):302-7.

3. Costa F, Sarno M, Khouri R, de Paula Freitas B, Siqueira I, Ribeiro GS, et al. Emergence of congenital Zika syndrome: viewpoint from the front lines. Ann Intern Med. 2016;164(10):689-91.

4. Kleber de Oliveira E, Cortez-Escalante J, Holanda De Oliveira WTG, do Carmo GMI, Pessanha Henriques CM, Coelho GE, et al. Increase in reported prevalence of microcephaly in infants born to women living in areas with confirmed Zika virus transmission during the first trimester of pregnancy - Brazil, 2015. Morb Mortal Wkly Rep. 2016;65(9):242-7.

5. Sarno M, Sacramento GA, Khouri R, do Rosário MS, Costa F, Archanjo G, et al. Zika virus infection and stillbirths: a case of hydrops fetalis, hydranencephaly and fetal demise. PLoS Negl Trop Dis. 2016;10(2):e-0004527. 
6. Calvet G, Aguiar RS, Melo ASO, Sampaio SA, de Filippis I, Fabri $\mathrm{A}$, et al. Detection and sequencing of Zika virus from amniotic fluid of fetuses with microcephaly in Brazil: a case study. Lancet Infect Dis. 2016;16(6):653-60.

7. Mlakar J, Korva M, Tul N, Popovic M, Poljšak-Prijatelj M, Mraz $\mathrm{J}$, et al. Zika virus associated with microcephaly. N Engl J Med. 2016;374(10):951-8.

8. Zanluca C, Melo VCA, Mosimann ALP, Santos GIV, Santos CND, Luz K. First report of autochthonous transmission of Zika virus in Brazil. Mem Inst Oswaldo Cruz. 2015;110(4):569-72.

9. Lopes MH, Miyaji KT, Infante V. Zika virus. Rev Assoc Med Bras. 2016;62(1):4-9.

10. Sai-Yin Wong S, Wing-Shan Poon R, Cheuk-Ying Wong S. Zika virus infection-the next wave after dengue. J Formos Med Assoc. 2016;115(4):226-42.

11. Chouin-Carneiro T, Vega-Rua A, Vazeille M, Yebakima A, Girod R, Goindin D, et al. Differential susceptibilities of Aedes aegypti and Aedes albopictus from the Americas to Zika virus. PLoS Negl Trop Dis. 2016;10(3):e0004543.

12. Carod-Artal FJ. Epidemiology and neurological complications of infection by the Zika virus: a new emerging neurotropic virus. Rev Neurol. 2016;62(7):317-28.

13. Dick GWA, Kitchen SF, Haddow AJ. Zika virus. I. Isolations and serological specificity. Trans R Soc Trop Med Hyg. 1952;46(5): 509-20.

14. Duffy MR, Chen TH, Hancock WT, Powers AM, Kool JL, Lanciotti RS, et al. Zika virus outbreak on Yap Island, Federated States of Micronesia. N Engl J Med. 2009;360(24):2536-43.

15. Watrin L, Ghawché F, Larre P, Neau JP, Mathis S, Fournier E. Guillain-Barré Syndrome (42 cases) occurring during a Zika virus outbreak in French Polynesia. Medicine (Baltimore). 2016;95(14):e3257.

16. Weaver SC, Costa F, Garcia-Blanco MA, Ko AI, Ribeiro GS, Saade $\mathrm{G}$, et al. Zika virus: emergence, biology, and prospects for control. Antiviral Res. 2016;130:69-80.

17. Freitas ARR, Angerami RN, von Zuben APB, Donalisio MR. Introduction and transmission of Zika virus in Brazil: new challenges for the Americas. Rev Inst Med Trop São Paulo. 2016;58:24.

18. Campos GS, Bandeira AC, Sardi SI. Zika virus outbreak, Bahia, Brazil. Emerg Infect Dis. 2015;21(10):1885-6.

19. Faria NR, Azevedo RSS, Kraemer MUG, Souza R, Cunha MS, Hill $\mathrm{SC}$, et al. Zika virus in the Americas: early epidemiological and genetic findings. Science. 2016;352(6283):345-9.

20. Paixão ES, Barreto $\mathrm{F}$, Teixeira $\mathrm{MG}$, Costa $\mathrm{MCN}$, Rodrigues LC. History, epidemiology, and clinical manifestations of Zika: a systematic review. Am J Public Health. 2016;106(4):606-12.

21. Pessôa R, Patriota JV, de Souza ML, Felix AC, Mamede N, Sanabani SS. Investigation into an outbreak of dengue-like illness in Pernambuco, Brazil, revealed a cocirculation of Zika, chicungunya, and dengue virus type 1. Medicine (Baltimore). 2016;95(12):e3201.

22. Salvador FS, Fujita DM. Entry routes for Zika virus in Brazil after 2014 World cup: new possibilities. Travel Med Infect Dis. 2016;14(1):49-51.

23. Musso D. Zika virus transmission from French Polynesia to Brazil. Emerg Infect Dis. 2015;21(10):1887.

24. Oehler E, Watrin L, Larre P, Leparc-Goffart I, Lastère S, Valour F, et al. Zika virus infection complicated by Guillain-Barré syndrome - case report, French Polynesia, December 2013. Euro Surveill. 2014;19(9):pii:20720.
25. Ministério da Saúde. Boletim: Microcefalia. Brasília: Agência de Saúde; 2016 [citado em 18 de maio 2016]. Disponível em: http:// portalsaude.saude.gov.br/index.php/cidadao/principal/agenciasaude/23753-microcefalia-ministerio-da-saude-confirma-1-384casos-no-pais.

26. Barcellos C, Xavier DR, Pavão AL, Boccolini CS, Pina MF, Pedroso $\mathrm{M}$, et al. Increased hospitalizations for neuropathies in Brazil as indicators of Zika virus infection, according to health information system data, Brazil. Emerg Infect Dis. 2016;22(11):1894-9.

27. Ministério da Saúde. Secretaria de Vigilância em Saúde. Departamento de Vigilância das Doenças Transmissíveis. Protocolo de Vigilância dos Casos de Manifestações Neurológicas com Histórico de Infecção Viral Prévia. Brasília: Ministério da Saúde; 2015. $10 \mathrm{p}$.

28. Ministério da Saúde. Secretaria de Vigilância em Saúde. Protocolo de vigilância e resposta à ocorrência de microcefalia. Versão 1.3. Brasília: Ministério da Saúde; 2016. 70 p.

29. World Health Organization. International Statistical Classification of Diseases and Related Health Problems $10^{\text {th }}$ Revision Version for 2007 [Internet]. Switzerland: World Health Organization; 2006 [citado em 15 junho 2016]. Disponível em: http://apps.who.int/ classifications/apps/icd/icd10online2007/

30. Oliveira CS, Vasconcelos PFC. Microcephaly and Zika virus. J Pediatr (Rio J). 2016;92(2):103-5.

31. Garcez PP, Loiola EC, Madeiro da Costa R, Higa LM, Trindade P, Delvecchio R, et al. Zika virus impairs growth in human neurospheres and brain organoids. Science. 2016;352(6287):816-8.

32. Cao-Lormeau VM, Blake A, Mons S, Lastère S, Roche C, Vanhomwegen J, et al. Guillain-Barré Syndrome outbreak associated with Zika virus infection in French Polynesia: a casecontrol study. Lancet. 2016;387(10027):1531-9.

33. Carteaux G, Maquart M, Bedet A, Contou D, Brugières P, Fourati $\mathrm{S}$, et al. Zika virus associated with meningo encephalitis. N Engl J Med. 2016;374(16):1595-6.

34. Ventura CV, Maia M, Ventura BV, Van Der Linden V, Araújo $\mathrm{EB}$, Ramos RC, et al. Ophthalmological findings in infants with microcephaly and presumable intra-uterus Zika virus infection. Arq Bras Oftalmol. 2016;79(1):1-3.

35. Martines RB, Bhatnagar J, Keating MK, Silva-Flannery L, Muehlenbachs A, Gary J, et al. Evidence of Zika virus infection in brain and placental tissues from two congenitally infected newborns and two fetal losses - Brazil, 2015. MMWR Morb Mortal Wkly Rep. 2016;65(6):159-60.

36. Agarwal R, Dhar V. Editorial - Big data, data science, and analytics: the opportunity and challenge for is research. Information Systems Research. 2014;25(3):443-8.

37. Bhavnani SP, Muñoz D, Bagai A. Data Science in Healthcare: implications for early career investigators. Circ Cardiovasc Qual Outcomes. 2016;9(6):683-7.

38. Mattmann CA. Computing: a vision for data science. Nature. 2013;493(7433):473-5.

39. Luquetti DV, Koifman RJ. Qualidade da notificação de anomalias congênitas pelo Sistema de Informações sobre Nascidos Vivos (SINASC): estudo comparativo nos anos 2004 e 2007. Cad Saúde Pública. 2010;26(9):1756-65.

40. Frias PG, Szwarcwald CL, Lira PIC. Avaliação dos sistemas de informações sobre nascidos vivos e óbitos no Brasil na década de 2000. Cad Saúde Pública. 2014;30(10):2068-80.

41. Victora CG, Schuler-Faccini L, Matijasevich A, Ribeiro E, Pessoa A, Barros FC. Microcephaly in Brazil: how to interpret reported numbers? Lancet. 2016;387(10019):621-4. 
42. Mello Jorge MHP, Laurenti R, Gotlieb SLD. Análise da qualidade das estatísticas vitais brasileiras: a experiência de implantação do SIM e SINASC. Cien Saúde Colet. 2007;12(3):643-54.

43. Ministério da Saúde. Agência Nacional de Saúde Suplementar (ANS). Dados Gerais: Beneficiários de planos privados de saúde, por cobertura assistencial (Brasil - 2006-2016) [Internet]. Rio de Janeiro: Ministério da Saúde; 2017 [atualizado em 31 de março 2017; citado em 15 junho 2016]. Disponível em: http://www.ans.gov. br/perfil-do-setor/dados-gerais

44. Boccolini CS, Carvalho ML, Oliveira MI, Boccolini PM. Breastfeeding can prevent hospitalization for pneumonia among children under 1 year old. J Pediatr (Rio J). 2011;87(5):399-404.
45. Boccolini CS, Boccolini PMM, de Carvalho ML, de Oliveira MIC. Padrões de aleitamento materno exclusivo e internação por diarréia entre 1999 e 2008 em capitais brasileiras. Ciên Saúde Colet. 2012;17(7):1857-63.

46. Organização Mundicial de Saúde. Centro Brasileiro de Classificação de Doenças. Universidade de São Paulo (USP). Novo código para Zika Vírus [Internet]. São Paulo: Centro Brasileiro de Classificação de Doenças; 2015 [atualizado em 17 de dezembro de 2015; citado em 15 junho 2016]. Disponível em: http://www.fsp.usp.br/cbcd/index. php/novo-codigo-para-zika-virus/ 